\title{
El logos sentiente, la aprehensión primordial de realidad y la impresión de realidad en la filosofía de Xavier Zubiri.
}

Eduardo Buenaventura Badía Serra ${ }^{1}$

Recibido en febrero de 2014 y aceptado en mayo de 2014

Resumen

El autor expone la hipótesis de que en la filosofía de Xavier Zubiri, la Aprehensión Primordial de Realidad y la Impresión de Realidad, que son las bases fundamentales de su Teoría de la Inteligencia, no son lo mismo y que por lo tanto hay que distinguirlas, para tener una comprensión adecuada de la filosofía de la inteligencia de este pensador.

Palabras claves

Aprehensión primordial de realidad, impresión de realidad, cristianismo, ciencia, realidad, inteligencia sentiente

\begin{abstract}
The author presents the hypothesis that, in philosophy, Xavier Zubiri, the Primordial Apprehension of Reality and the Impression of Reality, which are the cornerstones of his theory of intelligence, are not the same and therefore we must make a distinction between them in order to have a proper understanding of the philosophy of the intelligence of this thinker.

\section{Keywords}

Primordial apprehension of reality, impression of reality, Christianity, science, reality, sentient intelligence.
\end{abstract}

\section{NOTA INTRODUCTORIA.}

Este trabajo se presenta en seis partes. Su objeto es plantear una hipótesis en el sentido de que no son lo mismo la Aprehensión Primordial de Realidad y la Impresión de Realidad en la Teoría de la Inteligencia del filósofo Xavier Zubiri, y desarrollar dicha hipótesis.

\footnotetext{
1. Licenciado en Filosofía, Doctor en Química Industrial Email: ebbserra@yahoo.com.mx
} 
El planteamiento de la hipótesis y su desarrollo se encuentran efectivamente contenidos en las partes 3 y 4 . Las partes 1, 2 y 5.- pueden considerarse apoyos al trabajo en el sentido de explicar un poco la obra de Zubiri y particularmente los tres tomos que corresponden a su Teoría de la Inteligencia, así como la inclusión de algunos términos de significado muy específico en su filosofía y relativos a esta temática. La parte 6 , contiene la bibliografía utilizada.

De tal forma, las lecturas de estas partes pudieran perfectamente omitirse y concretarse en las que se refieren al asunto, esto es, las partes 3 y 4 , sirviendo el resto de mero apoyo.

\section{1.- LA FILOSOFIA DE XAVIER ZUBIRI.}

No es el objeto aquí hacer una detallada biografía de Zubiri, ni una descripción completa de la evolución de su pensamiento y del contenido de su obra. La vida de este gran filósofo es de sobra conocida y relatada, y la complejidad de la evolución de su pensamiento y de su obra misma son tan grandes que escapan al objeto de esta Monografía. Además, han sido múltiplemente estudiadas y analizadas a profundidad. Sólo se hace aquí una reseña pequeña como elemento introductorio al tema, que nos permita confirmar, en primer lugar, la rigurosidad y continuidad de su formación, así como reconocer el hecho de que Zubiri compartió, departió y fue acogido en los más rancios y elevados estratos del pensamiento europeo de la época, en los cuales fue catalogado como uno de los intelectuales de mayor valía del viejo continente, y dentro de los cuales se supo situar con clara y elevada propiedad.

Este apartado es, entonces, sólo introductorio. El objeto del trabajo será el exponer la hipótesis de que en la filosofía del gran filósofo vasco, la Aprehensión Primordial de Realidad y la Impresión de Realidad, bases fundamentales de su Teoría de la Inteligencia, no son lo mismo, contrario a la opinión bastante general que se sostiene en relación al asunto.

\subsection{Introducción Anecdótica.}

Erwin Schrodinger, uno de los más grandes científicos del siglo XX, en su primera lección en la Universidad de Berlín, en donde había sucedido a Max Planck en la cátedra de Física Teórica, comenzó con una frase de San Agustín: Hay una antigua y una nueva teoría de los quanta, y de ellas puede decirse lo que San Agustín de la Biblia: "Novum testamentum in vetere latet; vetus in novo patet" (El nuevo testamento está latente en el antiguo; el antiguo está patente en el nuevo). Un comienzo desconcertante para aquel auditorio, habituado al positivismo del pasado siglo, que nos ha servido, a última hora, una "ciencia sin espíritu ninguno, y por lo tanto, sin espíritu científico "Tomo la cita del ya viejo pero aún valioso trabajo del mismo Zubiri, “La idea de naturaleza. La nueva física" (Zubiri, 1934, p.2), escrito precisamente cuando él se encontraba 
en su etapa fenomenológica, previa a su etapa final metafísica que comienza con Sobre la Esencia. Y la tomo precisamente por que de Zubiri podría decirse lo mismo que del antiguo y del nuevo testamento, y que de la antigua y la nueva teoría física, es decir, que la obra de Zubiri está latente en toda la filosofía anterior, pero esta está patente en la obra de Zubiri.

La obra de Zubiri es, pues, una especie de nuevo testamento filosófico, en el cual toda la historia de la filosofía es un continuo e indispensable referente, pero a partir del cual esta historia se trastoca, se transforma.

\subsection{Introducción Biográfica.}

Xavier Zubiri nace en San Sebastián en el año 1898, y muere, a los ochenta y cinco años, en 1983.

A los 17 años, en 1915, ingresa al Seminario de Madrid y ya en 1920, a los 22, se licencia en Filosofía en el Instituto Superior de Filosofía de la Universidad de Lovaina, y obtiene además su Doctorado en Teología en Roma. Un año después, en 1921, se doctora en Filosofía en la Universidad de Madrid, y se ordena Diácono, afincándose en esa ciudad.

Cinco años después gana la cátedra de Filosofía en la Universidad de Madrid, la que ejerce, con algunas interrupciones, hasta 1935. Entre 1928 y 1930 disfruta de un permiso de estudios que lo lleva a Friburgo y a Berlín.

Gran conocedor de los idiomas antiguos y modernos, de la matemática y de las ciencias de la naturaleza; discípulo y compañero de estudios en Friburgo, de Husserl y de Heidegger; discípulo de Nicolai Hartmann y condiscípulo de Einstein, Schrodinger, Planck y Jaeger en Berlín; discípulo del sumeriólogo A. Deimel, quien le enseña las lenguas orientales antiguas; colega en París del príncipe Louis de Broglie en el campo de la física, de Benveniste en el de la filología, y de Maritain en el de la filosofía; Zubiri es un intelectual que se ubica y comparte con el gran mundo intelectual de la ciencia y de la filosofía, precisamente cuando estas son sacudidas por la irrupción del nuevo paradigma físico que se da a partir de 1905, y que sustituye al paradigma newtoniano y su ciencia normal en cuanto a la forma de ver e interpretar el universo y la realidad universal.

Católico, Zubiri se separa del orden sacerdotal, y reintegrado al estado seglar se dedica a construir el enorme edificio que constituye su filosofía. Pertenece a lo que se conoce como "Primera Generación del Siglo XX" en la filosofía española, tan rica y desafortunadamente poco apreciada en nuestro entorno latinoamericano. Discípulo de Ortega y de Heidegger, recoge de ellos su impacto historicista y existencialista; maestro de Marías, a quien le prologa su libro de Historia de la Filosofía; compañero de García Morente, Recaséns Ziches, 
María Zambrano, Gerardo Diego, Dámaso Alonso, Jiménez Caballero, García Lorca, Rafael Alberdi, José Gaos, Laín Entralgo, Merleau-Ponty, Sartre; asiduo colaborador de la Revista de Occidente. Publica en castellano la Fenomenología del Espíritu, de Hegel, en 1917, quien le influye profundamente sin hacerle caer en los descarríos del romanticismo alemán. Gran estudioso de la fenomenología de Husserl y del neokantismo, del positivismo francés y de la filosofía de Bergson. De Juan Zaragueta recibe su formación neoescolástica.

Dentro de esa formidable formación, Zubiri transita influenciado definitivamente por la ciencia, que emerge continuamente en su filosofía, pero también por un profundo catolicismo que le lleva a una especie de religacionismo teológico. “La vida del hombre no es un simple 'hecho' ni un puro 'posible', sino una misión impuesta al hombre por un Ser Superior", dice. Y es que "el hombre está religado a algo que no es exterior ni es constitutivo, sino que 'le hace ser'; no se encuentra sólo 'arrojado en el mundo' como señala el existencialismo, sino también religado por su raíz a un fundamento esencial, Dios”.

Sufre el embate del franquismo, tanto dentro como fuera de España, según se dice, por ser vasco y profesor universitario. Aun después del franquismo y de la guerra civil, cuando regresa a España, lo mantienen alejado de Madrid, en Barcelona, en donde también enseña en su universidad, hasta que al fin renuncia a ello en 1942 por medio de una excedencia sine die, debido a las presiones del régimen. (Hernáez, R., Xavier Zubiri, el hombre y su obra, separata).

\subsection{Influencia y evolución de su pensamiento.}

Las influencias en Zubiri son de suyo muy complejas, dada la amplitud de campos en los cuales incursionó como parte de su misma formación e incluso ya dentro de la práctica misma de su hacer filosófico. Si bien lo influencian de múltiple manera muchos filósofos anteriores y coetáneos, como el mismo Aristóteles, Husserl, Heidegger, Ortega y Bergson, considero que sería titánica, y a lo mejor infructuosa, labor, tratar de identificar, diferenciar y ponderar tanta influencia individual. Yo preferiría afirmar que las dos grandes influencias fueron, en primer lugar, el cristianismo, y en segundo lugar, la ciencia. Por ello, su filosofía ha sido considerada tanto un religacionismo teológico como una filosofía de la realidad, que antropológicamente él ha insistido en aclarar que no es ni un hilemorfismo aristotélico ni un materialismo dialéctico sino un materismo, concepto que desarrolla y sostiene en toda su obra Sobre el Hombre. (Xavier, Z., 1986, Sobre el hombre, Madrid: Alianza Editorial).

No es posible incluso analizar separadamente la forma en que su cristianismo y su ciencia le influyeron. Ambas influencias se dan como incardinadas dentro del todo reflexivo de su obra, característica este todo que Zubiri no va a perder y que mantendrá incluso desde sus primeros escritos. La obra zubiriana es unitaria y mantiene un estricto y consistente sentido. Zubiri insiste en la diversidad de formas, sentidos e intensidades en que puede ser vivido el cristianismo. Julián 
Marías, en su obra La situación intelectual de Xavier Zubiri, (Obras, Madrid, Ed. Revista de Occidente, 19602. T.V., pp. 478, 479, 480), nos lo dice: "Para él, esto no constituye un problema: Basta con ser cristiano sin dejar de ser lo que se es, ya sea judío, europeo, o cualquier otro; cada quien desde su propia mentalidad y su íntegra situación histórica y personal”. Y remarca, “Tengo puesta en Zubiri la mayor esperanza de que algún día exista en nuestro mundo algo que merezca con pleno rigor el nombre ilustre y problemático de filosofía cristiana". El hombre debe dejarse afectar e influenciar por su ser cristiano, y debe permanecer fiel a lo que la realidad le presenta, a su cristianismo y al resto de su situación social, histórica e intelectual.

De igual manera es fuerte y decisiva en él la influencia de la ciencia. Volviendo a la obra de Marías ya citada, puede decirse que Zubiri llegó a la filosofía por el camino de la ciencia. Para él, "la filosofía, tomada sin más, parece bastante insípida; y en cambio cuando se llega a ella por que las ciencias todas nos fuerzan, entonces y sólo entonces adquiere sentido y verdadera justificación", nos dice su alumno en el mismo artículo. No es posible tratar de conocer a Zubiri haciendo abstracción de la ciencia. Esta se presenta, de manera continua y sistemática, en toda su obra, y no como un adicionar conocimientos auxiliares al cuerpo de su filosofía sino como parte integrante y constitutiva de la misma. Ello se advierte en su obra medular: Sobre la Esencia, Teoría de la Inteligencia, y Sobre el Hombre, y además, en el resto, sobre todo en Espacio. Tiempo. Materia. Zubiri piensa que el saber científico logra efectivamente conocer la realidad a su manera propia, pero de un modo perfectamente real, por lo que la ciencia tiene mucho qué decir a la filosofía, aunque todo lo que le diga no sea todavía una sola palabra de filosofía. La ciencia es una realidad, y por lo tanto, la filosofía tiene que entendérselas con ella; constituye nuestro mundo, y luego es una de las determinantes de nuestra situación; es así parte intrínseca de la realidad del hombre que filosofa. Ya en Naturaleza, Historia, Dios lo va confirmando: "La filosofía consiste, precisamente, en el problema del ser, del mundo y de la teoría, planteados por la simple entrada de la inteligencia en sí misma”. (Zubiri, 1944, p. 39).

Se pueden identificar en Zubiri dos etapas claras: hasta 1944 se considera su etapa fenomenológica, en la cual destaca su obra Naturaleza, Historia, Dios. A partir de esa fecha inicia lo que se conoce como etapa metafísica, que se acostumbra comenzar con Sobre la Esencia, y en la que destacan El problema del hombre, escrita incluso antes que Sobre la Esencia, Cinco lecciones de filosofía, Inteligencia Sentiente, Inteligencia y Logos, Inteligencia y Razón, El Hombre y Dios, Sobre el Hombre, Espacio. Tiempo. Materia. Sin embargo, el cambio no es un rompimiento sino producto de un tránsito largo, en el que el mismo Zubiri va un poco como corrigiendo sus mismos deslizamientos, término que acostumbra utilizar para señalar los errores que históricamente se han dado, según él, en la filosofía. Ejemplo de ese transitar es su concepción del alma y del espíritu, que desemboca finalmente en el psiquismo, otro de los pilares fundamentales de su pensamiento, y de igual manera, su concepción de 
la estructura precisa de las notas constitutivas de la realidad humana. No le fue fácil al filósofo ese tránsito. En el ya lejano curso Cuerpo y Alma, (1950 - 1951), y sobre todo, en el otro El problema del hombre (1953 - 1954), había dado al alma una sustantividad y una independencia que más tarde le parecieron excesivas. Su explicación de la unidad del hombre, a pesar de intentar superar los dualismos, constante en toda su filosofía, seguía siendo hylemórfica y trataba de asegurar algunas explicaciones tradicionales que atribuían al alma una inmortalidad por su propia naturaleza. Estas especies de presiones dogmáticas se sostienen largamente, hasta que ya en El Hombre y su cuerpo, (Xavier, Z., 1973. El hombre y su cuerpo. Asclepio 25, 1973: 3-15), empieza a llevar a sus últimas consecuencias su idea de la unidad estructural entre lo psíquico y lo orgánico, cuestión que ya define con mucha precisión en Sobre el Hombre. (Xavier, Z., 1986. Sobre el hombre. Madrid: Alianza Editorial), Zubiri acabó pensando y afirmando que la psique es por naturaleza mortal y no inmortal, de modo que con la muerte acaba todo en el hombre o acaba el hombre del todo, aunque como teólogo siempre sostuvo que también el hombre resucita, si merece esa gracia o recibe esa gracia de Dios por la promesa de Jesús.

De igual manera es el tránsito y la evolución de su concepto de la esencia y de lo trascendental, también medulares en su obra, al cual habré de referirme sucintamente en el próximo apartado.

\subsection{Notas sobre su obra.}

Deseo aquí hacer una referencia breve a la obra de Zubiri, centrada esta en su metafísica, su antropología, su teoría de la inteligencia, su filosofía de la ciencia, y, agrego, su visión del problema teologal y del problema de Dios. Aunque todos los contenidos filosóficos están presentes en toda su obra, refiero aquella en la que con mayor énfasis se enfocan.

Unas notas sobre su Metafísica.

La metafísica de Zubiri, su famosa ya metafísica intramundana, está contenida principalmente en la obra Sobre la Esencia. (Xavier, Z., 1962, Sobre la esencia. Madrid: Alianza Editorial).

Lo esencial para Zubiri no es el ente, o el ser, o el hombre, o la idea, sino la realidad. Pero una realidad que considere las cosas, no tales como son sino como son, lo cual es lo propio de la actividad humana que es la filosofía. En el primer caso hay implicación de talidad; en el segundo, de trascendentalidad. No es que la filosofía sea ajena a lo que las cosas son talitativamente, sino más bien que su enfoque, el enfoque filosófico de las cosas, debe ser en función trascendental, lo cual significa no un disentir la función talitativa sino complementar su insuficiencia, colocándose por encima de ella. El aspecto talitativo entonces, ni es el único ni es el más radical de la esencia, aunque es parte de ella. La esencia es, para Zubiri, entonces, no sólo aquello según lo cual 
la cosa es tal realidad, sino aquello según lo cual la cosa es real. Y ese carácter por lo cual la cosa es real, que es la esencia, es el carácter trascendental, en el cual convienen formalmente todas las cosas y todas las notas, que está por encima de cualquier talidad, que es el orden de la realidad en cuanto realidad, y que es el orden al que pertenece la esencia. Zubiri provoca así el paso de lo talitativo a lo trascendental, lo cual constituye una constante en su filosofía. Pero, ¿Qué significa pasar entonces del orden talitativo al orden trascendental ? Pues, pasar del contenido de las notas a su unidad esencial, pasar plenamente al orden metafísico pero sin prescindir de la consideración talitativa. Es pasar del de-suyo al suyo, como razón formal y fundamento de la esencia, exigiendo tales notas (estudio talitativo), y haciendo que tales notas sean reales (estudio trascendental). El orden de la totalidad y el orden de la trascendentalidad son entonces dos órdenes intrínsicamente ligados. En síntesis, lo real, a) se pertenece (de suyo) a sí mismo (suyo) según su propio modo (individual ); con lo cual la esencia es un constructo (función talitativa) rico (función trascendental) y sólido (función estable).

Unas notas sobre su Antropología:

La Antropología de Zubiri se contiene medularmente en su obra Sobre el Hombre (Xavier, Z., 1986, Sobre el hombre. Madrid: Alianza Editorial).

El hombre, para Zubiri, no es animal racional sino animal de realidades, animal inteligente. Pero como la razón no es más que un tipo especializado de inteligencia y la inteligencia no es la capacidad de pensamiento abstracto y de la plena reflexión conciente, sino simplemente la capacidad de aprehender las cosas como realidades, animal inteligente y animal racional son cosas diferentes.

El animal racional sólo es un tipo de animal inteligente. El paso del hombre inteligente al hombre racional es un proceso evolutivo de índole genético no rectilíneo. Zubiri no pretende abandonar la animalidad del hombre, pues está presente en él pero en unidad estructural con la inteligencia. Al hacer su vida, el hombre, entre las posibilidades que tiene, elige unas y rechaza otras, de modo que la figura que el hombre determina en cada acto vital suyo depende en gran parte de sus propias decisiones. La necesidad que el hombre tiene de apropiarse unas posibilidades en vez de otras, hacen de él una realidad peculiar. En su antropología, Zubiri pretende resolver la dualidad hombre-naturaleza y hombre-historia, que más bien no son orientaciones que se excluyen entre sí sino complementarias. No se puede resolver el problema del hombre admitiéndolo sólo como conciencia o sólo desde el punto de vista científico o sólo desde el punto de vista filosófico, sino desde ambos puntos de vista. Zubiri responde a la dualidad de la antropología tomando al hombre como una unidad estructural, dinámica. Para él, el hombre es el resultado de un largo proceso de desarrollo, en el cual se recorren los siguientes pasos: Un acercamiento positivo-talitativo de la realidad humana; posterior toma talitativa, en apropiación, de esa 
realidad humana; análisis de la función trascendental de la talidad humana; y, finalmente, mostrar trascendentalmente el dinamismo de la realidad humana. Es entonces necesario conectar la realidad del hombre con el ser del hombre, con lo cual el ser se ve irremisiblemente remitido a la realidad. El hombre es, así, un constructo psico-orgánico, en el cual, la psique es sólo psique-de este cuerpo, y el cuerpo es sólo cuerpo-de esta psique".

Podría resumirse en cinco elementos fundamentales la concepción del hombre en Zubiri:

a) Una absoluta necesidad de situar al hombre en su realidad, para lo cual Zubiri hace uso de la ciencia y vincula a esta con la filosofía en una sola versión antropológica. El hombre sólo es animal de realidades si se le ve en una vinculación estructural de sus componentes científico y filosófico.

b) La eliminación del dualismo antropológico. El hombre es, formalmente, una unidad psico-orgánica sustantiva, una unidad sistemática de notas. No el hombre-naturaleza y el hombre-historia; no el hombre-materia y el hombre-conciencia; no el hombre como ser psico-físico y el hombre espiritual. El hombre como estructura psico-orgánica, en la cual la psique es psique-de el organismo y el organismo es organismo-de la psique. Aquí el famoso constructo del 'de' zubiriano.

c) La concepción de la génesis como un proceso de carácter material pero bajo un concepto diferente de materia, diferente del concepto aristotélico y del concepto materialista dialéctico. Zubiri habla de un "materismo", con el cual sustituye el hilemorfismo aristotélico y el materialismo dialéctico.

d) Una concepción dinámica del hombre. El hombre se va haciendo: Inicialmente trasciende en la animalidad por la estimulidad, para en un segundo momento trascender a su propia realidad por la psique. Esto se logra mediante sucesivas sistematizaciones, cada vez más perfectas. La vida entonces es una innovación que la sustantividad material da de sí por mera sistematización.

e) La concepción de la génesis como un dar de sí por medio de un proceso de elevación. Zubiri aquí supera las antiguas o anteriores concepciones medievales de la célula germinal; en la misma forma, supera de alguna manera la concepción del hombre como creación de un ser superior; e incluso el concepto evolucionista materialista dialéctico del Coacervado. El hombre brota de la sistematización de la materia.

Unas notas sobre Dios.

Este tema lo trata Zubiri principalmente en su obra El hombre y Dios. (Xavier, Z., 1984, El hombre y Dios. Madrid: Alianza Editorial).

Zubiri plantea rutas de acceso a Dios, y ante el fracaso de estas propone planos de explanación que se reducen a cuatro: La vida del hombre consiste en poseer 
haciendo religadamente su yo, un ser absoluto cobrado, relativamente absoluto. Ese ser absoluto es cobrado por la determinación física del poder de lo real como algo último, impelente y posibilitante. Como momento de las cosas y determinante del yo, el poder de lo real es más que la realidad, y por lo tanto el poder está fundado en una realidad absolutamente distinta de las cosas reales, pero las constituye como reales. Esta realidad es Dios. Así llega Zubiri a Dios, a un Dios que es una presencia fundante, una experiencia del hombre, siendo el hombre algo último, impelente y posibilitante; esta experiencia de Dios es individual, social e histórica: Allí descubrimos al Dios Autor, Actor y Agente.

Unas notas sobre su Teoría del Conocimiento.

Aunque de alguna manera se hablará de ello a partir del próximo apartado, desearía exponer aquí algunas generalidades sobre la Teoría del Conocimiento de Zubiri.

En primer lugar, el término mismo "Teoría del Conocimiento "no es empleado por el autor. Zubiri rechaza hablar de una "Epistemología" y de una "Teoría del Conocimiento" como tales, y por ello, hacer una referencia a dichas disciplinas no parecería del todo adecuado. Lo mismo sucede con la "Filosofía de la Ciencia", a la cual me referiré en próximo momento. Zubiri prefiere, en todo caso, referirse a una especie de "Filosofía de la Naturaleza" , y en lo que concierne a la cuestión epistemológica, como veremos, aclara que su obra es más una "noología". En todo caso, es más adecuado y preciso referirse a una "Teoría de la Inteligencia", que es realmente lo que es, que a una Teoría del Conocimiento. Esta Teoría de la Inteligencia, la expone en su trilogía Inteligencia Sentiente - Inteligencia y Realidad (Xavier, Z., 1984), Inteligencia y Logos, (Xavier, Z., 1984, Inteligencia y logos. Madrid: Alianza Editorial), e Inteligencia y Razón (Xavier, Z., 1984, Inteligencia y razón, Madrid: Alianza Editorial), escrita en tres tomos y considerada por muchos como su obra principal.

En su "Teoría de la Inteligencia", Zubiri, desde lo positivo de la "Impresión de Realidad" (Inteligencia Sentiente), se traslada a una realidad campal (Logos, como forma ulterior de la inteligencia), para finalmente trasladarse a una realidad mundanal (Razón, como forma ulterior de la inteligencia). Estos sucesivos traslados se hacen sin abandonar los momentos anteriores, que más bien eran ya contenidos en un prius en los ulteriores.

El hombre llega al conocimiento a través de un proceso que contempla cuatro momentos: a) Un examen de las ciencias, esto es, un acercamiento positivo talitativo a la realidad humana; b) Toma, o apropiación, talitativa de la realidad humana; c) Análisis de la función trascendental de la talidad humana; y d) Mostración trascendental del dinamismo de la realidad humana. Es decir, esto es, Ir de lo positivo a lo talitativo, y de lo talitativo a lo trascendental. 
Ello tiene una indiscutible relación con la forma en que el hombre siente: según él, en el ser vivo se da una estimulación inmediata o mediata que provoca una liberación biológica por susceptibilidad; es lo que llama el sentir. En el animal, hay un estímulo signitivo, con una liberación biológica por senticencia sensibilidad; es también un sentir. En el hombre, en cambio, hay ya un estímulo inmediato que provoca una liberación biológica por sensibilidad - intelección; es a lo que llama inteligir. El animal, entonces, libera biológicamente su estimulidad, se sitúa en el puro sentir. El hombre, en cambio, aprehende su realidad, con lo que siente inteligiendo. En este trascender en la animalidad hasta su propia realidad, el hombre se convierte en un animal de realidades.

Unas notas sobre su Filosofía de la Ciencia.

Como he dicho, hay en la obra de Zubiri una continua y estrecha interrelación entre filosofía y ciencia, aunque él insista en la no consideración de una filosofía de la ciencia. En su última obra, Espacio. Tiempo. Materia, (Xavier, Z., 2001, Espacio. Tiempo. Materia. Madrid: Alianza Editorial), se pudiera resumir su posición en tal sentido.

Esta obra se considera como un libro de cosmología, o de filosofía de la naturaleza, lo cual pudiera interpretarse modernamente como parte de la ciencia. Sin embargo, el mismo Zubiri deja claro que tiene sentido todavía hablar de una filosofía de la naturaleza como saber específico y distinto de la cosmología científica. Pero en la misma forma, la naturaleza como objeto material es común a la ciencia y a la filosofía, aunque no como objeto formal. Y es que la filosofía y la ciencia estudian a la naturaleza del mismo modo: Coinciden en el qué estudiar, pero no en el cómo.

Zubiri insiste en que "Espacio. Tiempo. Materia" es un libro de filosofía, esto es, de metafísica, y esto lo dice en referencia a toda su obra, aunque él mismo aclara que las consideraciones científicas y las filosóficas sobre la naturaleza no pueden suponer independencia total de la filosofía con respecto a la ciencia. Es lo que verdaderamente ocurre en él. Su filosofía es una constante pregunta sobre los efectos que la ciencia, e incluso la tecnología, tienen sobre el hombre y sobre la realidad. No sólo en "Espacio. Tiempo. Materia" se da esta situación. Ya en su lejana Naturaleza, Historia y Dios, en la que hace de la historia, o lo que es lo mismo, del hombre, el eslabón intermedio y mediador entre la Naturaleza y Dios, se puede identificar la dimensión natural en su filosofía. Sobre el Hombre es otra de sus obras en las que no es posible hacer una separación entre sus contenidos científicos y filosóficos, y en la que ambas disciplinas se imbrican de manera tal que, aunque su dimensión es claramente antropológica, sin consideraciones epistemológicas, o en todo caso, noológicas, actuales, no podría ser adecuadamente comprendida. Dice Antonio Ferraz, en la presentación de la primera reimpresión de Espacio. Tiempo. Materia, (Ferraz, 2001, p. III), que en dicho libro "filosofía y ciencia se conjugan con beneficio para ambas". 
La intensa urdimbre y trama filosofía - ciencia es tal en Zubiri, que, según refiere el mismo Ferraz en la obra citada (Ferraz, 2001, p. V), Ignacio Ellacuría, en la presentación del curso El hombre y Dios dejó dicho lo siguiente: "El intento de redacción de este curso llevó a comenzar el estudio sobre el hombre, y el estudio sobre el hombre llevó a un estudio sobre la materia, que fue concebido como un estudio en sí que no llegó a concluirse".

En síntesis, Zubiri intenta crear una filosofía no separada de la ciencia, una filosofía que interprete a la naturaleza bajo la óptica filosófica de la realidad, de manera que sea tarea de la ciencia averiguar las notas esenciales que hacen que lo real sea tal como es, esto es, que su asunto sea la talidad, y que sea tarea de la filosofía, o lo que es en él lo mismo, de la metafísica, el conceptuar lo que sea el orden talitativo analizando su estructura trascendental, el orden de la realidad, o de la respectividad. Así, bajo ese orden de ideas, lo físico no es patrimonio exclusivo de la ciencia, sino sólo lo talitativo que hay en él, esto es, lo empírico - factual, por que lo físico es, en totalidad, susceptible de una doble consideración, una consideración positiva y una metafísica. En ambas radica su formalidad.

En la ciencia, pues, hay una prioridad de la ratio cognoscendi sobre la ratio essendi, mientras que en la metafísica ocurre lo contrario.

Zubiri no deja de hacer incluso algunas consideraciones en relación con la inteligencia artificial, la cual, si bien es un recurso para la mecanización de la lógica formal, no puede llenar el papel de la inteligencia como concreción y codeterminación de lo orgánico. No es posible, pues, hablar de una inteligencia no sentiente, no impresiva, no biológica, pues lo biológico es una nota constitutiva de la sustantividad intelectiva. La inteligencia natural, entonces, no puede ser reducida ni asimilada por un complejo mecanismo algorítmico. (Hernáez, 1999, Zubiri y su filosofía de la actualidad: Inteligencia natural e inteligencia artificial (IA), en Filosofía, actualidad e inteligencia en Xavier Zubiri, http://www.zubiri.org/general).

\section{2.- LA TEORIA DE LA INTELIGENCIA DE ZUBIRI.}

2.1. El problema de la principialidad metafísica. El asunto en Sobre la Esencia - Sobre la Inteligencia.

Hay una especie de reclamo, o duda, en relación a por qué Zubiri escribió primero una obra sobre la esencia, es decir, su obra metafísica, y después, una sobre el conocimiento, esto es su teoría de la inteligencia. Sobre la esencia fue publicado en 1962, mientras que el tomo de Inteligencia Sentiente apareció en 1980. Esta duda la resuelve el mismo Zubiri precisamente en el prólogo a Inteligencia Sentiente - Inteligencia y Realidad. Considero necesario previo a transcribir parte de dicho prólogo, hacer las siguientes consideraciones: 
Sobre la esencia (Xavier, Z., 1985. Sobre la esencia. Madrid: Alianza Editorial), es la obra en que Zubiri desarrolla su concepto de realidad, pero el sentido preciso de lo expuesto en dicha obra sólo puede obtenerse a partir de los tres tomos de su teoría de la inteligencia (Xavier, Z., 1984, Inteligencia sentiente - Inteligencia y realidad; inteligencia y logos; inteligencia y razón. Madrid: Alianza Editorial). Debe recordarse que Zubiri prefiere hablar de una teoría de la inteligencia que de una teoría del conocimiento, pero en todo caso, para efectos de claridad, la referencia es la misma. En Inteligencia Sentiente es en donde se aclara su concepto de realidad, básico e imprescindible en toda su filosofía, y además, su momento esencial, ya vistos ellos epistemológicamente. Es, dice Zubiri en Inteligencia Sentiente, (Zubiri, 1984, p. 10), imposible una prioridad intrínseca del saber sobre la realidad ni de la realidad sobre el saber. El saber y la realidad son en su misma raíz estrictamente congéneres. El prólogo mismo a dicha obra lo comienza precisamente con esa aclaración (Zubiri, 1984, pp. 9 y 10):

"Publico este libro sobre la inteligencia muchos años después de haber publicado un libro sobre la esencia. Esto no es una mera constatación cronológica. Por el contrario tiene un sentido intrínseco que no será superfluo esclarecer. ¿Qué significa aquí "después"?. Para muchos lectores, mi libro "Sobre la esencia" estaba falto de un fundamento por que estimaban que saber lo que es la realidad es empresa que no puede llevarse a cabo sin un estudio previo acerca de lo que nos sea posible saber. Esto es verdad tratándose de algunos problemas concretos. Pero afirmar en toda su generalidad que esto sea propio del saber de la realidad en cuanto tal es algo distinto. Esta afirmación es una idea que en formas distintas ha venido constituyendo la tesis que ha animado a casi la totalidad de la filosofía moderna desde Descartes hasta Kant: es el “criticismo". El fundamento de toda filosofía sería la crítica, el discernimiento de lo que se pueda saber. Pienso, sin embargo que esto es inexacto. Ciertamente la investigación sobre la realidad necesita echar mano de alguna conceptuación de lo que sea saber. Pero esta necesidad ¿es una anterioridad? No lo creo, por que no es menos cierto que una investigación acerca de las posibilidades de saber no puede llevarse a cabo, y de hecho nunca se ha llevado a cabo, si no se apela a alguna conceptualización de la realidad. El estudio sobre la esencia tiene muchas afirmaciones acerca de la posibilidad del saber. Pero a su vez es cierto que el estudio acerca del saber y de sus posibilidades incluye muchos conceptos acerca de la realidad. Es que es imposible una prioridad intrínseca del saber sobre la realidad ni de la realidad sobre el saber. El saber y la realidad son en su misma raíz estricta y rigurosamente congéneres. No hay prioridad de lo uno sobre lo otro. Y esto no solamente por condiciones de hecho de nuestras investigaciones, sino por una condición intrínseca y formal de la idea misma de realidad y de saber".

Por esa vía resuelve Zubiri el asunto de la principialidad de la esencia y el conocimiento. 


\subsection{Relación de la obra.}

Ya en 1979, en Respectividad de lo real, escribía Zubiri (Zubiri, 1979, p. 25): "A diferencia de la filosofía clásica, pienso que es forzoso partir de una "idea distinta de inteligencia", inteligencia sentiente, y en su virtud de una "idea distinta de realidad", realidad como de suyo. Zubiri concuerda con la visión biológica sostenida en el sentido que hay que salir de una visión engañosa de realidad sostenida por la concepción mecanicista cartesiana - newtoniana, pues que dicha visión es así lo demuestran tanto el pensamiento oriental relativo a la naturaleza orgánica, dinámica, viviente, de la misma, como la física moderna, que habla del tejido cósmico compuesto por estructuras cuyas realidades últimas no son ya aquellos lejanos ladrillos elementales de la materia sino los tejidos dinámicos de sucesos interdependientes (Atlan, 1991, p. 36).

El hombre funda sus facultades en una realidad de suyo (reismo), cuya respectividad de sentido se funda en la respectividad sentiente o mera actualización (inteleccionismo).

Estas tres facultades humanas, que no son potencias, no son tres acciones sino tres momentos especificantes de una sola acción una e indivisa: Comportarse con la realidad. Son tres expresiones de la actualidad primaria de la realidad en la inteligencia, en la voluntad y en el sentimiento temperante del hombre. En el siguiente cuadro, que tomo de "Xavier Zubiri. El hombre y su Obra", de Roberto Hernáez (Hernáez, sin fecha, Xavier Zubiri, el hombre y su obra, http://ensayo.rom.uga.edu, p.15 ), se resumen:

\begin{tabular}{|l|l|l|l|}
\hline $\begin{array}{l}\text { Facultades } \\
\text { Humanas }\end{array}$ & $\begin{array}{l}\text { Inteligencia } \\
\text { Sentiente }\end{array}$ & $\begin{array}{l}\text { Sentimiento } \\
\text { Afectante }\end{array}$ & Voluntad Tendente \\
\hline $\begin{array}{l}\text { Respectividad } \\
\text { Mundanal o } \\
\text { remitente }\end{array}$ & $\begin{array}{l}\text { Respectividad } \\
\text { sentiente de mera } \\
\text { actualización }\end{array}$ & $\begin{array}{l}\text { Respectividad } \\
\text { afectante, } \\
\text { respectividad de } \\
\text { sentido }\end{array}$ & $\begin{array}{l}\text { Respectividad } \\
\text { tendente, } \\
\text { respectividad de } \\
\text { sentido }\end{array}$ \\
\hline Proceso del Sentir & $\begin{array}{l}\text { Momento de } \\
\text { suscitación }\end{array}$ & $\begin{array}{l}\text { Momento de } \\
\text { modificación tónica }\end{array}$ & $\begin{array}{l}\text { Momento de } \\
\text { respuesta }\end{array}$ \\
\hline $\begin{array}{l}\text { Modo de } \\
\text { Actualización }\end{array}$ & $\begin{array}{l}\text { Verdad-realidad } \\
\text { aprensible }\end{array}$ & $\begin{array}{l}\text { Belleza - realidad } \\
\text { atemperante }\end{array}$ & $\begin{array}{l}\text { Bondad - realidad } \\
\text { optable }\end{array}$ \\
\hline Disciplina & Noología & Estética & Ética \\
\hline
\end{tabular}

Luego entonces, la inteligencia se funda en la impresión de realidad, el sentimiento en la afección de realidad, y la voluntad en la tendencia a la realidad, conformando así el proceso sentiente en el hombre: La intelección sentiente, el sentimiento afectante y la voluntad tendente. Esto significa que la intelección no es un acto de una facultad ni de una conciencia, sino que es en sí misma un acto de aprehensión, siempre de tipo sensible, o mejor, sentiente. La función de lo sensible no es plantear un problema a la inteligencia sino ser la primaria vía de acceso a la realidad. 


\subsection{Inteligencia Sentiente, Logos Sentiente y Razón Sentiente.}

El hombre comprende mediante tres modos o fases que se despliegan no de una manera lógica, si no cronológica, de la manera siguiente:

En un primer momento se da la instalación básica en la realidad, que da la realidad pura y simple. Es la Aprehensión Primordial de Realidad. En esta fase, el hombre aprehende el mundo real que se encuentra a su alrededor sin capacidad para diferenciar entre los distintos elementos que lo componen. Las cosas son, así, indiferenciadamente reales.

En un segundo momento ya es posible dicha diferenciación, la diferenciación de las cosas, nombrarlas y entender su mutua relación. Aquí ya se está ante lo que es en realidad lo real de la aprehensión de realidad. Es el logos, que es siempre, como la inteligencia en la fase anterior, sentiente. Las cosas son, aquí, diferenciadamente reales.

Finalmente, en un tercer y último momento, la razón, con la cual ya el hombre puede explicar metódicamente lo que las cosas son y por qué son de esa manera. Es el más alto nivel de comprensión, el modo ulterior de intelección. Aunque dentro de la razón pudiera asimilarse la ciencia, no es necesariamente la ciencia, por que el hombre también tiene otras formas de comprender su realidad, de explicarse lo que son y por qué son así las cosas. La razón, como los dos momentos anteriores, es también y necesariamente sentiente. Aquí, las cosas son ya diferenciadamente reales en profundidad.

Zubiri hace del primero de estos tres modos, la aprehensión primordial de realidad, el más importante pero no suficiente. Las cosas son reales en aprehensión, pero para entender por qué son reales ya no es suficiente instalarse directamente en la realidad de una forma pura y simple. Por ello, los tres modos, inteligencia sentiente, logos sentiente y razón sentiente son indisolubles y como se ha dicho, se constituye por ellos la intelección.

\section{3.- PLANTEAMIENTO DE LA HIPÓTESIS: NO SON LO MISMO “APREHENSION PRIMORDIAL DE REALIDAD” QUE “IMPRESIÓN DE REALIDAD”.}

\section{Hipótesis:}

"No son lo mismo 'Aprehensión Primordial de Realidad' que 'Impresión de Realidad' en la Teoría de la Inteligencia de Xavier Zubiri. La 'Impresión de Realidad' se identifica como el acto de inteligir, esto es, con la intelección. La 'Aprehensión Primordial de Realidad' más bien se identifica con la facultad de inteligir, es decir, con la inteligencia sentiente. La 'Aprehensión Primordial de Realidad' corresponde al segundo momento de la 'Impresión de Realidad', se identifica entonces con la formalidad de la 'Impresión de Realidad' y no con su 'contenido'. 


\section{4.- DESARROLLO DE LA HIPÓTESIS.}

\subsection{Primer Acercamiento: Estructura dinámica del Logos Sentiente.}

Zubiri se opone a la tesis inicial de la filosofía desde Parménides, y que en buena medida persiste en la actual filosofía, de que inteligir es posterior a sentir, y que esta posterioridad es una oposición. Para Zubiri, al contrario, sentir e inteligir no son dos actos numéricamente distintos sino sólo dos momentos de un solo acto de aprehensión sentiente de lo real, esto es, de la inteligencia sentiente, cuyo acto único y unitario es Impresión de Realidad. Para Zubiri, actualidad no es el carácter de acto de algo, que es la tesis sostenida por los latinos, sino la índole formal del acto de inteligencia sentiente. Lo que expresa la tesis latina es mera actuidad: Los virus, por ejemplo, han tenido actuidad desde hace millones de años, pero sólo hasta hace unos pocos tienen actualidad. La intelección humana es entonces formalmente mera actualización de lo real en la inteligencia sentiente.

Existen distintos modos de actualizar lo real: a) Un modo primario y radical, la Aprehensión Primordial de Realidad, (Inteligencia Sentiente); un modo según el cual lo real se actualiza no sólo en y por sí mismo sino también entre otras cosas, que nace en la realidad y está desde siempre en la realidad, la Aprehensión en Actualización Diferenciada, (Logos Sentiente); y un modo según el cual lo real se actualiza como momento del mundo, entendiendo como mundo lo trascendental del campo, el Campo en el Mundo Sentido, (Razón Sentiente). El logos, pues, nace en la realidad y se apoya y funda en la Impresión de Realidad. La razón nace y marcha en la realidad y se apoya a su vez en el logos sentiente. Toda intelección ulterior es ulterioridad impresiva por que la actualización primordial es sentiente, acontece en impresión: por ello, el logos es sentiente y la razón es sentiente.

Zubiri, en Inteligencia y Logos (Xavier, Z., 1984, Inteligencia y logos. Madrid: Alianza Editorial), trata de reafirmar la diferencia entre la aprehensión primordial de realidad como forma elemental, radical y exclusiva de intelección, y su forma ulterior, más rica pero no por ello más ni tan importante, una aprehensión actualizada diferencial, el Logos Sentiente. Si bien en la aprehensión primordial de realidad se encuentran ya presentes los dos momentos de formalidad individual y de formalidad campal, estos están en ella como dos momentos de una sola y misma formalidad de realidad de la cosa, pero en una forma inmediata tal que no es posible diferenciarlos. Por ello, la aprehensión primordial de realidad es una aprehensión compacta, dado que no puede desdoblarse en sus dos momentos de formalidad individual y de formalidad campal, desdoblamiento que es el que posibilita el enriquecimiento de aquella primera y más importante forma de intelección. Ciertamente se presentan en la aprehensión primordial de realidad las tres dimensiones de la cosa real, esto es, el esto, el cómo, y el qué; pero estas tres dimensiones están unitariamente compactas en la cosa directamente aprehendida como real. En cambio, en la 
simple aprehensión, en actualización diferencial, estas dimensiones quedan actualizadamente discriminadas. Al no haber en la aprehensión primordial de realidad, posibilidad de diferenciación de las tres dimensiones de la cosa real, no puede entonces haber ni percepto, ni ficto, ni concepto; estos quedan para la simple aprehensión en distancia, esto es, son formas de aprehensión en actualización diferencial, y en ellas hay un desdoblamiento de los momentos que permite inteligir una cosa entre otras mediante un movimiento de impelencia de la cosa real al campo de la realidad (toma de distancia), y un segundo momento del intentum, que permite inteligir desde el campo lo que la cosa es en realidad (intelección intelectiva).

Pero ello no significa que se ha logificado la inteligencia sino simplemente que se ha actualizado, es decir, que se ha inteligizado el logos. El tomar distancia es un olvidarse de la cosa en sí para dar toda la importancia a la cosa para sí, sin que ello signifique situarse fuera de la realidad. Es un distanciamiento desde la cosa misma en la cosa misma que permite poder ver mi cosa, mi realidad, el de suyo.

Lo anterior permite poder elaborar cinco tesis que ayudarán posteriormente a sustentar la hipótesis que he expuesto y que es el objeto de este trabajo: que no son lo mismo la Aprehensión Primordial de Realidad y la Impresión de Realidad en la Teoría de la Inteligencia de Zubiri:

\section{Primera tesis:}

El primer paso del movimiento intelectivo es la Aprehensión primordial de realidad (intelección primordial). Esta aprehensión es compacta por que no puede efectuar el desdoblamiento de los dos momentos de formalidad de realidad, es decir, los momentos de formalidad individual y de formalidad campal. Sin embargo, ya se presentan en esta aprehensión primordial de realidad las tres dimensiones de la cosa real, esto es, el esto, el cómo y el qué, pero en forma compacta, unitariamente, en la cosa directamente aprehendida como real. Esta aprehensión primordial de realidad es el momento fundamental del proceso intelectivo, y en ella se fundan tanto la simple aprehensión como el juicio, formas estas más ricas pero sólo ulteriores de intelección.

Segunda tesis:

El segundo paso del movimiento intelectivo es la Simple Aprehensión (Intelección Retraída). Esta es sólo el primer momento del proceso de aprehensión en actualización diferenciada. Parte de lo real ya aprehendido en aprehensión primordial, en impresión de realidad, pero toma distancia de lo real dentro de su campo de realidad. Es una forma de intelección mediada de la impresión de realidad mediante un movimiento de retracción en el que la intelección elabora un complejo conjunto de simples aprehensiones (perceptos, fictos y conceptos) cuyo carácter formal es lo que la cosa sería en realidad. En la simple aprehensión se desdoblan ya los momentos de formalidad individual y de formalidad campal, lo que permite inteligir una cosa entre otras. Es el momento que corresponde al 
movimiento de impelencia de la cosa real al campo de la realidad, que provoca una suspensión intelectiva, un tomar distancia de la cosa pero en ella y desde ella misma.

Tercera tesis:

El tercer paso del movimiento intelectivo es la Aprehensión Firme (Intelección Dual). Esta intenta ya inteligir la cosa real, no como lo que sería sino como lo que la cosa es en realidad. Es el segundo momento del proceso de aprehensión en actualización diferenciada, que se logra mediante el movimiento del intentum como movimiento de reversión a la cosa real para inteligir desde el campo lo que la cosa es en realidad desde el orbe de lo que sería. En este paso se presenta ya un discernimiento, un juicio, una afirmación. Este intentum desde el campo tiene entonces un carácter de intención afirmativa de lo que la cosa es o no es en realidad. Es, pues, la unidad del 'esto', el 'cómo' y el 'qué' que conforman el 'sería', expresada en el 'es'. La afirmación es, por lo pronto, una intelección en reversión distanciada de lo que la cosa es en realidad. Es una intelección dinámica reversiva del distanciamiento de algo ya aprehendido en una aprehensión primordial. Es, en una palabra, el logos, pero como fundado en una aprehensión primordial de realidad, el logos sentiente entonces.

\section{Cuarta Tesis:}

La afirmación reviste tres formas distintas: Posicional, pro-posicional y predicativa, como diferentes funciones de la cosa de que se juzga, diferentes sólo por su carácter formalmente sentiente, y como formas de recorrer reversivamente la distancia de lo irreal a lo que lo real es en realidad. Las tres formas anteriores son entonces formas del intentum, y a su vez, formas de unidad de lo campal y de lo individual como unidad de la formalidad de realidad, unidad que significa, precisamente, la fuerza de realización, la fuerza de la realidad. La unidad más fuerte es la posicional, la menos fuerte es la predicativa, siendo la pro-posicional una unidad de fuerza intermedia.

Quinta tesis:

El movimiento total de la intelección entonces: a) nace en Impresión de Realidad, en Aprehensión Primordial de Realidad; b) se enriquece en Simple Aprehensión, mediante un movimiento de distanciación impelente; y c) retorna a la Impresión de Realidad en un movimiento de intención retractiva basado en tres formas de afirmación: posicional, pro-posicional o complexiva, y predicativa o conectiva. En otras palabras, el Logos nace en impresión de realidad, se sitúa en perspectiva, para volver a impresión de realidad en forma de 'afirmación'. Esta es, precisamente, la cuestión.

\subsection{Segundo Acercamiento: los tres estratos de la sustantividad del viviente en el marco del sentir y del inteligir.}

Las acciones humanas, las habitudes y las estructuras constituyen los tres estratos de la sustantividad del viviente. Las dos primeras constituyen el nivel 
operativo del hombre como animal de realidades. Las estructuras por su lado constituyen el nivel constitutivo. Dentro de estos niveles se sitúa la inteligencia sentiente como habitud, como modo que tiene el hombre de habérselas con las cosas. La habitud no es acción, sino lo que hace posible toda acción. Estas acciones y estas habitudes enmarcan en los seres vivientes los procesos del sentir, y particularmente, en el hombre, el proceso de inteligir sentientemente. El hombre se halla entre cosas, externas unas, internas otras, que le mantienen en actividad no sólo constante sino primaria. El viviente se halla colocado entre cosas, tiene su locus determinado entre ellas; pero también está situado, dispuesto, en determinada forma frente a ellas, tiene su situs frente a ellas. Esta colocación y disposición del viviente entre las cosas le determinan su estado, un estado vital, un equilibrio dinámico, una actividad en quiescencia. El estado entonces es la quiescencia de un equilibrio dinámico reversible y modificable; dinámico y reversible por que la respuesta efectora restablece el equilibrio alterado por la suscitación; y modificable, por ampliación o por retracción, y en todo caso por modulación, del ámbito de la actividad vital en que el viviente consiste.

Esta quiescencia, este movimiento estacionario, es precisamente la influencia del locus que provoca el situs, y por ello, no hay situación sin colocación. Y este estado vital, como microproceso de las acciones del viviente, se refleja en un macromodelo cuando el momento de respuesta se revierte sobre la suscitación, se vuelve estímulo y genera una nueva acción. El locus viene a ser entonces un carácter esencial pero no exclusivo del viviente sino más bien compartido. El situs en cambio es, además de esencial, un carácter exclusivo del viviente. (Zubiri, X., 1984, Inteligencia sentiente - Inteligencia y realidad. Madrid: Alianza Editorial, apéndice 3, pp. 89 - 97 ) (Zubiri, X., Sobre el hombre. Madrid: Alianza Editorial, capítulo I, Las acciones humanas, pp. 11 - 18).

En esta sucesión de modificaciones del estado vital, el viviente se posee a sí mismo mediante su comportamiento, y genera el esquema de sus acciones, es decir, su comportamiento. Es la vida, como autoposesión en decurrencia, en transición de un estado a otro como proceso de estados. La vida es una actividad vital en transición de estados, pero que no da a las cosas sino a sí misma. Esta actividad vital se compone de dos vertientes ya precisadas: El comportamiento, que da a las cosas entre las que el viviente se halla situado; y la autoposesión, que da a sí misma. El comportamiento, en la vida, es entonces la mediación de la autoposesión; y la precisa unidad de ambas vertientes constituye la mediatización. Esto es lo que constituye la actividad vital de todo ser viviente, este proceso de estados, esta continua mediatización de sus vertientes.

En este proceso de las acciones humanas, en su decurrencia, el estado vital modifica y transita hacia un nuevo estado: esto constituye el carácter procesual de la autoposesión: modificaciones continuas del equilibrio, desde estados energéticos iniciales de tipo quiesciente hasta estados energéticos alterados; pero todos, cuali-cuantitativamente nunca iguales. Y lo mismo así, constituye 
la reversibilidad del equilibrio: equilibrio inicial - equilibrio restablecido equilibrio alterado.

Pero en este proceso de estados que es la vida, el viviente aprehende estímulos, estímulos como todo lo que suscita una respuesta, ya sea inmediatos o signitivos. El esquema de las acciones es entonces un esquema del sentir, del sentir como proceso sentiente compuesto por tres momentos: suscitación, según el cual las cosas modifican el estado vital y el viviente responde adquiriendo un nuevo estado; modificación tónica, en el que la suscitación modifica el estado en el sentido de alterar el tono vital que el viviente posee; y respuesta, el momento accional, el estímulo como efección estimulada. Mediante ellos como acción indivisa y única, el hombre se comporta estimúlicamente. A diferencia con el animal, que aprehende, es afectado y responde, en el hombre la unidad del sentir viene dada por tres momentos diferentes: Intelección, sentimiento y volición como correspondientes a la suscitación, a la modificación tónica y a la respuesta. El hombre, entonces, debe necesariamente hacerse cargo de sus realidades, pero no en una situación estimúlica sino que real. No se agota, pues, el hombre, en el puro sentir, sino se abre a la realidad.

Pero el sentir del hombre y el sentir animal sitúan el momento aprehensor, y en el sentir del hombre, la Impresión de Realidad. Es cosa de gradualidades esenciales: en todo ser vivo, la estimulación puede ser inmediata o mediata, esto es, el estímulo puede estar presente o no presente; el grado del sentir es más o menos indefinido, es una mera susceptibilidad. En el animal, el estímulo es ya signitivo, remite a algún estímulo no presente, hay en el sentir ya una sensibilidad, aunque difusa, una, entonces, senticencia; el momento aprehensor es pura estimulación suscitante, y el momento de respuesta se da mediante movimientos, reflejos, automáticos o adaptados.

En el hombre, el estímulo es inmediato, responde a lo presente como contenido del estímulo mismo, es ya realidad; es una sensibilidad más centralizada, es Inteligencia Sentiente. El momento aprehensor es por ello una realidad estimulante, la intelección. El momento de afección tónica es un sentimiento afectante. Y el momento de respuesta es una volición tendente, una tendencia del hombre a su realidad. Por la inteligencia sentiente, el sentimiento afectante y la voluntad tendente, el hombre se encuentra con las cosas como realidades, pero además, construye realidades.

Estas tres formas diferentes del sentir, en todo ser vivo, en el animal, y en el hombre, son producto de posición y de tiempo. En algunas de ellas se identifican la Impresión de Realidad y la Aprehensión Primordial de Realidad.

El proceso del sentir como proceso de suscitación y respuesta es sólo el primer estrato de la sustantividad del viviente. Es el más aprensible por que es el más externo, pero no es suficiente: Por bajo de la suscitación - respuesta hay un 
estrato más hondo, constituido por el modo de habérselas con las cosas, por la manera de enfrentarse con las cosas. Esto es lo que se llama Habitud. Por la habitud, las cosas no actúan ni suscitan, tan sólo quedan en cierto respecto con el viviente. Este mero quedar es la actualización, y el carácter de las cosas así actualizado a este respecto es la formalidad. Las tres habitudes más radicales, las tres maneras más radicales de habérselas con las cosas son: Nutrirse, sentir e inteligir, habitudes distintas pero no mutuamente excluyentes. No es la habitud el estrato más radical. Partiendo de las acciones, que el viviente ejecuta, y marchando hacia dentro de él, se halla la habitud como estrato subyacente de las acciones. La habitud es parte, junto con las acciones humanas, del nivel operativo del hombre. La inteligencia sentiente, como se verá luego, es una habitud; por ella, pues, las cosas se actualizan, adquieren formalidad.

Pero la sustantividad en el orden de suscitación - respuesta y en el orden de la habitud - respecto formal, es decir, la sustantividad como tensión y como habitud, no son sino la consecuencia de las estructuras, de la sustantividad como estructura. Las estructuras del viviente constituyen su modo de realidad, su índole propia, representa la totalidad de los momentos constitutivos de una realidad en su precisa articulación, en unidad coherencial primaria. Sólo en las estructuras está el momento formal constitutivo de la sustantividad. En la tensión y en la habitud tenemos tan sólo la sustantividad en su momento operativo. En la estructura, la sustantividad es, pues, suficiencia constitutiva en orden a la independencia y al control; aquí es donde se aprehende, con rigor, la diferencia entre el hombre y el animal, la diferencia esencial, por que en las estructuras se halla la esencia de toda realidad, y en esa esencia se radica la 'Impresión de Realidad' y la 'Aprehensión Primordial de Realidad' en lo que ambas tienen de coincidente como en sus diferencias. Esto, a objeto de este trabajo, es medular.

Es preciso entonces desde ya separar las dos habitudes que radicalmente se distinguen en la escala zoológica: la habitud del puro sentir estímulos, a la que responde la formalidad del estímulo, y la habitud de inteligir los estímulos como realidades, a las que corresponde la formalidad de realidad. Se trata, pues, de la habitud del sentir y de la habitud del inteligir, del puro sentir y del inteligir. Separamos el puro sentir, por que en la habitud del inteligir, que es, por ser algo intrínsecamente uno con la función del sentir, 'inteligir sentientemente', se encuentra así la dimensión de Impresión de Realidad, y también la dimensión de Aprehensión Primordial de Realidad.

\subsection{Tercer Acercamiento: Impresión de Realidad y Aprehensión Primordial de Realidad en el marco del sentir y del inteligir.}

Al hombre no le basta con que haya cosas reales, con el mero darse cuenta, sino que el hombre necesita que esas cosas le estén presentes; y las cosas le están presentes al hombre desde el hombre mismo, de acuerdo al modo de enfrentarse con ellas. 
Las cosas le están presentes al hombre primeramente por los sentidos. Pero el sentir no es aquí algo secundario, algo meramente residual, ni el sólo suministrar los datos de que la inteligencia se sirve para resolver el problema de conocer lo real, como diría el racionalismo, ni tampoco la mera intuición sensible del empirismo. Más bien, el dato sensible es un dato de la realidad. La función de lo sensible no es plantear un problema a la inteligencia, sino la primaria vía de acceso a la realidad. Lo sentido es, entonces, dato de realidad. El carácter sensible de nuestra intuición es, no una presencia todo lo inmediata que se quiera, sino una presencia en impresión. Sentir es la presencia impresiva de las cosas, no una mera intuición sino intuición en impresión.

Pero impresión es afección, y como toda afección es subjetiva, lo sensible, como mera afección del sujeto, queda desligado de lo real. La impresión es también, sin embargo, algo más, es momento de alteridad, y por eso también, lo sensible es a una un dato de la realidad y un dato para la intelección de lo real.

El hombre no sólo siente impresivamente las cualidades de las cosas, sino que siente impresivamente la realidad de las cosas. La alteridad aquí se constituye por su contenido pero también por su formalidad de realidad. Contenido y realidad son dos momentos de una sola impresión, la 'Impresión de Realidad'.

Hasta aquí se puede hacer un primer y elemental acto selectivo: La Impresión de Realidad no es un momento propio de las acciones vitales de todos los seres vivos y de los animales, sino sólo y exclusivamente del hombre. Se presenta en el sentir del hombre, que es, como se ha visto, no un puro sentir sino un sentir intelectivo. La Impresión de Realidad es una Aprehensión sensible propia de las acciones humanas provocadas por sus habitudes características, y se ubica en el momento del inteligir, de la intelección: Es la realidad estimulante del momento aprehensor. En ese preciso momento adquiere el hombre la Impresión de Realidad. No es cuestión de susceptibilidad, ni de senticencia, sino de sensibilidad.

La Impresión de Realidad es entonces la estructura esencial de la sensibilidad humana. La Impresión de Realidad es sensible. Y aunque en ella aparece ya el momento de realidad, formalmente no constituye el inteligir en cuanto tal. La Impresión de Realidad es, sin más, el momento propio del sentir humano. Por ella, la sensibilidad humana no es puro sentir sino sentir. La Impresión de Realidad es, pues, el 'acto' formal de inteligir. Como es la alteridad como momento absolutamente esencial, presencia de algo otro para el animal mismo, y no lo que páticamente hace el animal, la Impresión de Realidad es el momento modal de la impresión, el acto aprehensor de una inteligencia sentiente. No es una impresión sensible subjetiva. Es más bien la forma en que se da el carácter inespecífico de la realidad. Zubiri da un ejemplo: La impresión de un color rojo tiene dos dimensiones, lo específico, el color rojo, y lo inespecífico, lo real. 
La Impresión de Realidad es lo que primaria y radicalmente tenemos en la intelección. Es la aprehensión primaria y radical de lo real. En lo que tiene de impresión es un sentir, y en lo que tiene de realidad es intelección. Por tanto, el acto de tener Impresión de Realidad es intelección sentiente.

Los momentos de la Impresión de Realidad son, por lo tanto, dos: un primer momento, que es el sentir, el momento de impresión que califica al acto aprehensor como acto de sentir: Es el contenido; y un segundo momento, que es la realidad sentida, el momento de realidad que califica al acto aprehensor como aprehensión de realidad o inteligir: es la formalidad. La inteligencia sentiente consiste en que el inteligir mismo no es sino un momento de la impresión: el momento de la formalidad de su alteridad. (Zubiri, 1984, p. 84). $Y$ esto es medularmente importante para poder establecer diferencias entre la Impresión de Realidad y la Aprehensión Primordial de Realidad. La índole formal de la Impresión de Realidad la constituye la unidad de sus dos momentos.

Desearía aquí puntualizar lo más amplia y detalladamente que pueda esta cuestión. Recurro a lo contenido en el Capítulo IV de Inteligencia Sentiente - Inteligencia y Realidad, y particularmente al apartado I, La impresión de realidad, y al Apéndice 3, La inteligencia sentiente como facultad. (Zubiri, X., 1984, capítulo IV, La estructura de la aprehensión de realidad: Intelección sentiente, en Inteligencia sentiente - Inteligencia y realidad. Madrid: Alianza Editorial, pp. 75 - 97).

Dice Zubiri:

- Los momentos de la impresión de realidad son dos: el momento del sentir (impresión), y el momento del inteligir (impresión de realidad). (Zubiri, 1984, pp. 76 - 79);

- la unidad formal de ambos momentos es precisamente la intelección sentiente. (Zubiri, 1984, p. 79);

- el inteligir es facultad de realidad. (Zubiri, 1984, p. 80);

- sentir e inteligir son dos momentos de un solo acto, de una impresión una y única, de la impresión de realidad. (Zubiri, 1984, p. 81);

- el sentir siente la realidad; el inteligir intelige lo real impresivamente. (Zubiri, 1984, p. 81);

- la impresión de realidad, en su unidad estructural, es un hecho. (Zubiri, 1984, p. 82);

- la impresión de realidad es un solo y único acto, acto de la aprehensión primordial de realidad. (Zubiri, 1984, p. 82);

- la impresión de realidad es sentir intelectivo, intelección sentiente. (Zubiri, 1984, p. 82).

El asunto es que Zubiri no parece diferenciar entre Intelección Sentiente e Inteligencia Sentiente, aunque repetidamente identifica a la primera con la impresión de realidad, con el acto, con el hecho producido por una facultad que 
es precisamente la inteligencia sentiente. Ya en el mismo capítulo citado dice (Zubiri, 1984, p. 83): Prefiero hablar de inteligencia sentiente, comprendiendo en esta denominación, tanto el sentir intelectivo como el inteligir sentiente. Esta indistinción es, para mi, medular. En mi opinión, la aprehensión primordial de realidad es la facultad que tiene el hombre para actualizar lo real; luego, es, pues, facultad, recurso, medio, inteligencia sentiente. El acto, el hecho, lo formalizado, la formalidad resultante, eso es la impresión de realidad, la intelección sentiente. No es lo mismo, entonces, intelección sentiente (acto), que inteligencia sentiente (facultad).

El que la inteligencia sentiente es facultad lo afirma Zubiri en el apéndice 3 del capítulo citado (Zubiri, 1984, p. 89). Y aquí entra él en su amplia consideración de lo que son facultad y potencias. En el caso de la inteligencia sentiente hay dos potencias, la potencia del sentir y la potencia del inteligir (Zubiri, 1984, pp. 90 y 91). Aquí se advierte de nuevo la indistinción entre intelección e inteligencia sentientes. La unidad estructural de ambas potencias constituye la facultad, y esta unidad es la inteligencia sentiente (Zubiri, 1984, p. 91). De ello se deriva que el acto de impresión de realidad se realiza utilizando la facultad que él mismo llama Inteligencia Sentiente (Zubiri, 1984, p. 91). Y aquí un par de consideraciones que estimo importantes:

la impresión de realidad es un hecho, un acto, y por tanto, hecho es también el sentir intelectivo o la intelección sentiente. La conceptuación de facultad estructuralmente compuesta de potencia sentiente y intelectiva es a mi modo de ver, repito, la única conceptuación científica del hecho de la impresión de realidad. (Zubiri, 1984, pp. 91 y 92); y luego:

la inteligencia sentiente es una habitud, un modo de habérselas con las cosas. (Zubiri, 1984, p. 92). Ya he señalado esto anteriormente.

En virtud de ello, pienso, las cosas quedan en cierto respecto formal, esto es, se formalizan. Pero el que las cosas queden o se actualicen por la inteligencia sentiente no significa que es por esta que son, sino que son gracias a esta, es decir, que gracias a la inteligencia sentiente se actualizan. Esa habitud, pues, que es la inteligencia sentiente, es acción pero no estructura; la estructura es hecho, acto, quiescencia; esa habitud que es la inteligencia sentiente es facultad, potencia. (Zubiri, 1984, p. 95).

En la página 96 del libro citado expresa Zubiri que la unidad estructural de inteligencia y sentir es determinante de la habitud de intelección sentiente, cuyo acto formal es la impresión de realidad. En cuanto determinante de esa habitud, la estructura unitaria sentir - inteligencia es la facultad de inteligencia sentiente. (Zubiri, 1984, p. 96). El medio, el campo y el mundo, en cuanto sentidos intelectivamente, son la obra de la inteligencia sentiente como facultad. (Zubiri, 1984, p. 97). 
Es mi opinión, entonces, que: la inteligencia sentiente, siendo facultad, es la manera como la realidad está siendo formalizada; la intelección sentiente, en impresión de realidad, es la realidad misma ya formalizada.

Zubiri afirma (Zubiri, 1984, p. 256), que hasta este momento he usado indiscernidamente las expresiones de impresión de realidad, <intelección de lo real en y por sí mismo > y <aprehensión primordial de realidad>. Pero ahora conviene distinguirlas. Este es un reconocimiento expreso y claro de que, al margen de muchas similitudes, existen diferencias entre impresión de realidad y aprehensión primordial de realidad; esto es, no son lo mismo.

Ya en el capítulo primero de Inteligencia Sentiente - Inteligencia y Realidad (Zubiri, 1984, p. 20), Zubiri hace alguna diferenciación entre inteligencia e inteligir: una facultad se descubre en sus actos, dice, y agrega: los actos no se consideran como actos de una facultad sino como actos en y por sí mismos. En todo este libro me referiré, pues, a la 'intelección' misma, y no a la facultad de inteligir, esto es, a la inteligencia. Parece claro ahí que la intelección es un acto en y por sí mismo, y que la inteligencia es, precisamente, la facultad mediante la cual se realiza.

También puede verse la identificación que hace Zubiri entre acto y hecho. (Zubiri, 1984, p. 20): trátase, pues, de un análisis de los actos mismos. Son hechos bien constatables y debemos tomarlos en y por sí mismos y no desde una teoría de cualquier índole. Los hechos son actos conscientes de índole diversa, dice. (Zubiri, 1984, p. 21). Y precisamente la intelección es el darse cuenta de los hechos, de los actos, de lo que ya está presente. (Zubiri, 1984, p. 22). Deberá tenerse muy clara, entonces, la diferencia que Zubiri establece entre facultad, hecho y acto. Estos dos últimos son lo mismo, y no corresponden precisamente a la aprehensión primordial de realidad, sino la primera, la facultad. Lo dice expresamente el mismo Zubiri: en primer lugar, el acto constitutivo de la aprehensión primordial de realidad. Hablo de acto constitutivo para facilitar la frase, porque no es un acto sino un modo del acto de intelección. (Zubiri, 1984, p. 260).

Sucede que la compleja terminología empleada por Zubiri, y su muy particular uso del lenguaje, unido ello a la constante repetición de las temáticas, hace difícil la comprensión correcta del significado de sus posiciones. Con Zubiri, precisa ir puntualizadamente.

Ciertamente, Zubiri identifica la intelección como aprehensión. La intelección es un 'acto' de aprehensión, dice. (Zubiri, 1984, p. 25). Esta identificación siento que sólo se aclara mucho después cuando se identifica y determina ese tipo especial de aprehensión que es la aprehensión primordial de realidad.

El asunto no es fácil. 
La aprehensión primordial de realidad no es lo que formalmente constituye la intelección, sino que es la modalidad primaria de la intelección de lo real en y por sí mismo. Esta modalidad consiste en que lo aprehendido lo es precisivamente en intelección atentiva. (Zubiri, 1984, p. 261). Es, pues, aquella aprehensión mediante la cual aprehendemos impresivamente la realidad de lo real. (Zubiri, 1984, pp. 64 y 65). En ella, la formalidad de realidad está aprehendida directa, inmediata y unitariamente como formalidad de realidad. Veamos cómo la define Zubiri:

esta aprehensión de la cosa real como algo, previo a su modalización ulterior, constituye a su vez un modo propio y primario de intelección. Es justo lo que llamo Aprehensión Primordial de Realidad. (Zubiri, 1984, p. 256). Si percibo un árbol con todas sus notas, yo puedo no fijarme sino en una sola nota suya, en el color verde. Esta nota está dada en sistema con otras, pero puedo fijarme sólo en ella. Entonces esta nota es aprehendida en aprehensión primordial de realidad aunque no sea en sí misma una sensación elemental, esto es un término separado de los demás [...] un sistema tan complejo como un paisaje, si lo aprehendo solamente en y por sí mismo es, como aprehensión primordial de realidad, algo tan simple como la aprehensión de una sola nota. La modalidad es esencial a la intelección. Y como modalidad la aprehensión primordial abarca, repito, desde la aprehensión de una sola nota hasta la aprehensión de un sistema tan enormemente complejo como un paisaje. (Zubiri, 1984, p. 259).

Inteligir y sentir constituyen estructuralmente una sola facultad, la inteligencia sentiente. (Zubiri, 1984, p. 13). El sentir humano y el inteligir no sólo no se oponen sino que constituyen en su intrínseca y formal unidad un solo y único acto de aprehensión. Este acto en cuanto sentiente es impresión, en cuanto intelectivo, es aprehensión de realidad. (Zubiri, 1984, p. 13).

Intento ahora llegar a lo que es Aprehensión Primordial de Realidad.

Lo específico de la inteligencia es estar en realidad, y estar en realidad es aprehender las cosas como reales. Por estar en realidad, hay. Esto es la primera dimensión de la inteligencia. El acto físico de estar en inteligir. Las cosas son inteligibles, pero para que sean inteligibles deben ser inteligendas. Y son inteligendas por que, sean lo que sean, pertenecen al hombre mismo. El hombre mira las cosas desde aquello que el hombre es entre ellas, y el haber propio de lo que es el hombre por sí mismo antes que intelija las cosas, es el bien, el agathon.

En el estar en inteligir hay, entonces, tres dimensiones: a) Las cosas son inteligibles; b) Las cosas son inteligendas; y c) Las cosas son lo que el hombre quiere que sean. Estas tres dimensiones se dan siempre, por que el hombre, en cuanto inteligente, en cualquier situación suya entre las cosas, está atenido a ellas. 
La aprehensión primordial de realidad es la facultad, el modo cómo acceder a la realidad sentida. Por ella se formaliza la realidad. La inteligencia es el mecanismo por el cual se llega a la intelección.

El atenimiento del hombre a la realidad de las cosas es lo que se llama Aprehensión Primordial de Realidad: atenimiento a la realidad en el bloque compacto del ser y de la idea.

Vuelvo ahora por un momento a la aprehensión misma: La aprehensión es en el animal, momento del sentir cualitativamente diverso de la afección y la respuesta, pero que junto con ellos origina una acción única e indivisa: Comportarse estimúlicamente, es decir, sentir. La aprehensión es en el hombre, momento del sentir, pero que junto con la afección y la respuesta permite a este abrirse desde la estimulación misma a los estímulos como realidades. En el hombre, en el momento aprehensor, la realidad es estimulante. El momento aprehensor es como el acto primario del hombre en el sentir (intelección); después vienen el momento de afección tónica (sentimiento) y el momento de respuesta (volición). Las cosas que primariamente aprehendemos, en su manera de quedar en mi aprehensión, son la realidad. La realidad es un momento que pertenece formalmente a la aprehensión en su primigenia inmediatez. La realidad no es un extra, no es un fuera, no es un allende - la aprehensión, sino ser de suyo lo que es la aprehensión misma. La realidad es un “en' - la aprehensión".

Aprehensión de las cosas como realidad es, pues: el acto primario, exclusivo y radical de la inteligencia. Es el acto formal de la inteligencia. No es una acción sino una habitud, o sea, lo que hace posible toda acción, algo subyacente a toda acción. No es conocimiento, por que el conocimiento no es algo primario y radical de la inteligencia, sino que es un modo ulterior de intelección. En el hombre, la aprehensión de lo real modifica sus sentimientos y los lanza a una respuesta de tipo volitivo. Con ello, la unidad procesual humana es aprehensión de lo real, sentimiento de lo real, volición de lo real.

\section{¿Qué es entonces Aprehensión Primordial de Realidad?}

Es el modo primario de la intelección, aprehensión de la cosa real como algo, previo a su modalización ulterior, como modo propio y primario de intelección. Los otros modos de intelección son por eso, no primordiales sino ulteriores. Coincide con la mera intelección de la cosa real y por sí misma, y por tanto, con la Impresión de Realidad.

Pero se distinguen:

La aprehensión primordial de realidad es aprehensión de algo en y por sí mismo solamente como algo en y por sí mismo, y de una manera directa, inmediata y unitaria, no por representaciones ni imágenes, ni por inferencias o 
razonamientos. El solamente modaliza la aprehensión primordial de realidad. La aprehensión primordial de realidad modaliza, fija perceptivamente, como una sola nota el algo percibido. No es lo que formalmente constituye la intelección, sino que es la modalidad primaria de la intelección de lo real en y por sí mismo. El logos y la razón son modos ulteriores de la intelección, sólo posibles después de la aprehensión primordial de realidad, meros sucedáneos de la aprehensión primordial de realidad.

Intento puntualizar esta distinción citando al mismo Zubiri:

- Por el momento de fuerza de imposición, la impresión de realidad hace que lo aprehendido en aprehensión primordial de realidad no sea solamente un juicio sino realidad en y por sí misma. La fuerza de imposición 'impone' el contenido formalmente, con lo que se realiza el acto de impresión de realidad. (Zubiri, 1984, p. 66);

- los dos momentos constitutivos de la unidad de la impresión de realidad son la función talificante y la función transcendental. Talificación y transcendentalización son los dos aspectos inseparables de lo real. Constituyen la unidad estructural de la impresión de realidad. (Zubiri, 1984, p. 125);

- en definitiva, la inteligencia sentiente intelige la realidad en todos sus modos, y los transciende en la unidad de todos ellos. La inteligencia sentiente es aprehensión impresiva de lo real. Y esta impresión de lo real es constitutivamente modal y transcendental. Esto es justamente, impresión de realidad;

- toda impresión tiene un tercer momento, la fuerza de imposición de lo aprehendido sobre el aprehensor. (Zubiri, 1984, p. 52). Con ello, Zubiri está señalando una diferencia fundamental entre impresión de realidad y aprehensión primordial de realidad: esta última carece de fuerza de imposición; sin ella, no puede ser igual a la primera. Debe recordarse que los tres momentos de la impresión son Afección, alteridad y fuerza de imposición;

- en la página 134 de Inteligencia Sentiente - Inteligencia y Realidad, Zubiri expone algo con lo cual podríamos identificar a la inteligencia sentiente como facultad y a la impresión de realidad como acto, como hecho de esa facultad (Zubiri, 1984, p. 134). Dice Zubiri: que las cosas actúen sobre la inteligencia, es algo innegable [...] y es el resultado de aquella actuación, la esencia formal del acto [...] como hecho sólo tenemos la impresión de realidad. Esto es, la impresión de realidad es acto, hecho; la inteligencia sentiente es la actuación que hace posible el acto;

- el término formal de la intelección sentiente es siempre y sólo realidad. En su virtud, la realidad está sentientemente inteligida de modo directo, en y por sí misma, como impresión de realidad. (Zubiri, 1984, p. 223);

- el contenido de cada cosa real queda así inscrito, por así decirlo, en la misma impresión de realidad que nos dio la cosa real anterior. (Zubiri, 1984, p. 251); 
- inteligir, repito, es así, constitutiva y formalmente, estar también aprehendiendo la pura y simple realidad, esto es, lo que las cosas son 'de suyo' en cuanto tales. (Zubiri, 1984, p. 252);

- la unidad intrínseca y formal de aquellos tres momentos (sentir lo real, mera actualización, instalación), es lo que constituye la inteligencia sentiente. ( Zubiri, 1984, p. 252 );

- lo real está sentido en impresión de realidad. ( Zubiri, 1984, p. 255 ).

Hay un concepto zubiriano que ayudaría a identificar impresión de realidad y aprehensión primordial de realidad, y a la vez a reconocer sus diferencias; es el concepto de oblicuidad (Zubiri, 1984, pp. 223, 224, 227, 228). Este concepto permite identificar y diferenciar además la realidad y el ser, y cómo la impresión de realidad se liga y condiciona con el ser siendo este sólo ulteriormente. Expongo este concepto de oblicuidad en el apartado 5 de este trabajo, en el que se detalla alguna terminología zubiriana.

\subsection{Conclusión: En lo que coinciden y se diferencian la Aprehensión Primordial de Realidad y la Impresión de Realidad.}

De todo lo expuesto puedo resumir aquí aquello en lo que coinciden y se diferencian Aprehensión Primordial de Realidad e Impresión de Realidad:

$1^{\circ}$ La Impresión de Realidad es un acto aprehensor. Este acto aprehensor es la Aprehensión Primordial de Realidad, y lo lleva a cabo la Inteligencia Sentiente.

$2^{\circ}$ Impresión de Realidad y Aprehensión Primordial de Realidad coinciden con la mera intelección de la cosa real en y por sí misma.

$3^{\circ}$ La Impresión de Realidad es un único acto completo, compuesto por dos momentos, el momento del sentir y el momento de la realidad sentida, en unidad formalmente estructural. Este acto es la Aprehensión Primordial de Realidad.

$4^{\circ}$ La Impresión de Realidad y la Aprehensión Primordial de Realidad sólo se presentan en el sentir propio del hombre, es decir, en el inteligir sentiente. No se presentan, ni en el puro sentir animal, ni en las formas ulteriores de intelección que tiene el hombre.

$5^{\circ}$ Ambos, Impresión de Realidad y Aprehensión Primordial de Realidad, se ubican en el momento suscitante del sentir, es decir, responden a una modificación del estado vital, a una estimulación, a una presencia de estímulos inmediatos y no signitivos.

$6^{\circ}$ Por lo que sólo por la Impresión de Realidad y por la Aprehensión Primordial de Realidad, y sólo por ellos, se puede abrir el hombre desde los estímulos mismos a los estímulos como realidades. 
$7^{\circ}$ La Impresión de Realidad se identifica como el 'acto' de inteligir, esto es, con la intelección. La Aprehensión Primordial de Realidad más bien se identifica con la 'facultad' de inteligir, es decir, con la inteligencia sentiente.

$8^{\circ}$ La Aprehensión Primordial de Realidad corresponde al segundo momento de la Impresión de Realidad, se identifica entonces con la 'formalidad' de la Impresión de Realidad y no con su 'contenido'.

\section{ALGUNA TERMINOLOGÍA ZUBIRIANA RELATIVA AL TEMA.}

Afirmación: fase del movimiento intelectivo opuesta a la retracción. Intelección en reversión distanciada de lo que la cosa real es en realidad, hecha dentro de lo real mismo. "Ir" de una cosa a otra "entre" las demás.

Afirmación Posicional: aquella que, contrario a lo que acontece en las otras formas del juicio, la cosa de que se juzga no está previamente aprehendida en una simple aprehensión que la califica. Es decir, lo que se aprehende no está inteligido previamente.

Afirmación Predicativa: aquella en la que se dice algo de algo mediante un verbo, y en la que aquello de que se juzga desempeña la función de ser sujeto del juicio.

Afirmación Proposicional: aquella en que lo real ya aprehendido no está aprehendido sólo como real, sino que está ya aprehendido como algo que por su parte está ya calificado desde una simple aprehensión.

Clausura Cíclica: lo que hace que el hombre se eleve a la realidad.

Cómo: forma en que la cosa sistematiza sus notas de una cierta manera.

Compacción: de la cosa real, es la abolición de la diferencia entre el momento individual y el momento campal que se da cuando la cosa real se aprehende en aprehensión primordial de realidad.

Concepto: forma de simple aprehensión, realidad terminada en libre "qué", lo concebido en la concepción, realidad en su mero "sería" terminal, forma en que se aprehende el "qué” en simple aprehensión.

Construcción: transformación de la postulación fundada en el "sería" a la postulación fundada en el "es".

Constructo: el estado constructo de toda nota es no ser "nota+de" sino "notade". Mientras la nota sea nota es físicamente "nota-de": es un constructo físico. Cada cosa real es un constructo de nota. 
De-suyo: unidad intrínseca y formal de los tres caracteres: actualidad, en propio y prius. Expresión y conceptuación de esos tres caracteres o momentos.

Desrrealizar: suspensión del contenido que aquí y ahora es real. Suspender aquello en que está realizada "la" realidad.

Dimensiones de la cosa real: el "esto", el "cómo" y el "qué". El "esto" y el "cómo" configuran la cosa; el "qué" es la cosa así configurada. Las tres dimensiones reducidas a término de simple aprehensión, dan lugar a tres formas de simple aprehensión: el percepto, el ficto y el concepto.

Distancia: unidad en desdoblamiento que se presenta cuando una cosa se aprehende entre otras.

En propio: el calor es caliente "en propio" porque el calor calienta siendo caliente. El ser caliente "en propio" no consiste formalmente en estar ordenado a una respuesta, sino que es caliente formalmente "en propio", no está aprehendido estimúlicamente sino realmente. No es calor-estímulo sino calor-realidad.

Es: forma en que generalmente se expresa la unidad del "esto", del "cómo" y del "qué", que constituye el "en realidad".

Esto: forma en que queda actualizada la cosa real en una dimensión propia suya.

Estructura: donde está el constitutivo formal de la realidad humana.

Estructura de desdoblamiento de toda cosa real: aquella mediante la cual esta adquiere un doble momento, un momento individual y un momento campal.

Fantasía: intelección fantástica.

Ficción: simple aprehensión de la cosa como un "cómo" ficto. Cosa ficta en la realidad.

Ficto: es una forma de simple aprehensión. Término del movimiento intelectivo creador del "cómo". Realidad en ficción.

Formalización: no es una acción sino un 'mero quedar': Es la unidad de contenido y de formalidad.

Fuerza de Realización: es la fuerza de la unidad del momento campal y del momento individual, que se funda en las tres formas de afirmación, la posicional, la proposicional y la predicativa, expresadas estas en orden de fuerza ascendente. 
Hacia: modo de la realidad abierta mediante el cual se intelige la campalidad como momento distinto, con lo cual la cosa real queda distanciada de otras cosas reales en " la " realidad.

Intención: momento interno del intentum.

Intentum: tensión dinámica de revertir a lo real, formalmente dentro ya de la realidad, dentro de esta cosa real [...] movimiento hacia la cosa. Intento, intención.

Irreal: manera de tener que ver con lo real, que consiste en un "des" del "de suyo". Modo "desrreal" de estar en la realidad. Modo de estar en la realidad desrrealizadamente, esto es, sin que esta tenga un contenido determinado pero envolviéndola físicamente.

Irrealidad: unidad intrínseca y formal de actualización de "la" realidad física y de realización libre de su contenido. Es el "sería".

Juicio: intención afirmativa. Intelección modalizada de una aprehensión primordial de realidad. Intelección en reversión distanciada.

Logos: movimiento intelectivo en cuanto afirmación. Es siemprey necesariamente logos sentiente.

Movimiento de Impelencia: aquel que provoca una distanciación de lo que la cosa es en realidad, con el objeto de inteligir lo que una cosa entre otras es en realidad. Es un "pararse a considerar la cosa".

Movimiento del Intentum: aquel mediante el cual se intelige desde el campo lo que la cosa es en realidad. Es un "referirnos desde el campo a la cosa".

Nota: sos tanto la propiedad, la cualidad, etc., como también las partes constitutivas. Las notas pueden ser: Adventicias (presuponen el sistema ya constituido y pertenecen a él por la acción de factores extrínsecos al sistema); Constitucionales (tienen un origen causal exterior, pero son en sí mismas y formalmente las que forman el sistema); y Constitutivas (las que confieren a la cosa real sustantiva su básica sustantividad, su unidad coherencial primaria. Son el sistema básico de las notas constitucionales). Las notas son el principio de la sustantividad, aquello de lo que están constituidas las cosas. Una nota es siempre "nota-de" las demás.

Oblicuidad: es el co-sentir. El término formal de la intelección sentiente es siempre y sólo realidad. En su virtud, la realidad está sentientemente inteligida de modo directo en y por sí misma como 'impresión de realidad'. Esta realidad así aprehendida en impresión, 'es' ulteriormente. Esta ulterioridad está, pues, 'co-sentida' al sentir la realidad. La manera de sentir intelectivamente la 
ulterioridad es ' co-sentirla'. No está sentida directamente sino indirectamente. Si se quiere, la realidad está sentida en 'modo recto'; la ulterioridad está sentida en 'modo oblicuo'. Esta ublicuidad es justo el 'co-sentir', y lo cosentido es el 'ser'. Por ello, la impresión de realidad es apertura transcendental al mundo. El 'ser' es, así, el momento oblicuo de lo aprehendido en impresión de realidad, siendo lo oblicuo, la aprehensión de lo real. El 'ser' no es sino el momento oblicuo de lo aprehendido en impresión de realidad.

Percepto: forma de simple aprehensión. "Esto" en cuanto percibido. "Esto" de la cosa en cuanto mero término de percepción. Forma primaria y posibilidad misma de toda simple aprehensión. Forma en que se aprehende en simple aprehensión el "esto".

Postulados: enunciados de los caracteres que tiene el "contenido" de la "realidad" de lo postulado.

Postular: terminar "determinado" de la realidad en lo esto o en lo otro.

Primeras formas de Simple Aprehensión: son el percepto, el ficto y el concepto.

Principio de Inteligibilidad: aquello respecto de lo cual queda re-actualizada una cosa real.

Quiescencia: no es quietud, esto es, un acto de los efectores, sino un modo de respuesta. Es un estado vital.

Prius: el momento del prius es el momento físico de lo aprehendido en la aprehensión. Es un momento del "ya" que expresa que lo estimulante queda en la aprehensión como algo que es estimulante " antes " de estar estimulando y precisamente para poder estimular.

Realidad: es sólo un momento propio de cada cosa real, según el cual, esta, al ser en y por sí misma real, es sin embargo en y por sí misma "algo más". No es existencia sino ser "de suyo". Es estructuralmente ser antes de ser existencia. Es un "de suyo" que de suyo puede realizarse en esta cosa o en otra. Es la física dimensión campal de las cosas reales.

Realización: movimiento intelectivo en "la" realidad de la intelección judicante.

Retracción: intelección de la cosa real dejando en suspenso lo que es en realidad. Esfuerzo de suspensión en movimiento propio por el cual, mediante un movimiento de impelencia, sin abandonar la cosa real nos mantenemos en ella pero solamente como punto de apoyo para un repliegue intelectivo que deje en suspenso lo que esa cosa es "en realidad". Liberación del "en realidad" apoyándonos en "la" realidad. 
Sería: unidad de realidad y retracción. Carácter del contenido de las cosas reducido a principio de inteligibilidad. Modo irreal, no en sentido gramatical sino en sentido de "la" realidad en modo de libre contenido.

Simple Aprehensión: intelección en impelencia. Intelección de un real principio de inteligibilidad. Intelección retractiva de lo que la cosa "sería".

Sustantividad: es el sistema clausurado y cíclico de notas constitutivas, y su razón formal es la suficiencia constitucional, o sea, el tener una unidad clausurada y cíclica. La sustantividad no es sustancialidad.

Sustantividad Humana: el subsistema parcial + la clausura cíclica. En el subsistema parcial no hay sustantividad, esta la adquiere por el momento de la clausura cíclica.

Unidad Coherencial Primaria: la materia es unidad coherencial primaria.

\section{BIBLIOGRAFÍA.}

Atlan. H., Con razón y sin ella. Intercrítica de la ciencia y del mito, Barcelona: Tusquets.

Hernáez, R., 1999, Filosofía, actualidad e inteligencia en Xavier Zubiri, "http://www.zubiri.org/general Hernáez, R., sin fecha, "Xavier Zubiri. El hombre y su obra", http://ensayo.rom.uga.edu/filosofos/spain/ zubiri/introd.htm

Marías, J., La situación intelectual de Xavier Zubiri. Madrid: Ed. Revista de Occidente.

Zubiri, X., 1934, La idea de naturaleza. La nueva física. http://ensayo.rom. uga.edu

Zubiri, X., 1986, Sobre el hombre. Madrid: Alianza Editorial.

Zubiri, X., 1944, Naturaleza, historia, Dios. Madrid: Editora Nacional.

Zubiri, X., 1973, El hombre y su cuerpo. Asclepio 25 ( 1973 ): 3 - 15.

Zubiri, X., 1959, El problema del hombre. Revista Indice 120 ( 1959 ): 3-4

Zubiri, X., 1985, Sobre la esencia. Madrid: Alianza Editorial.

Zubiri, X., 1984, El hombre y Dios. Madrid: Alianza Editorial.

Zubiri, X., 1984, Inteligencia Sentiente, Inteligencia y Realidad. Madrid: Alianza Editorial.

Zubiri, X., 1984, Inteligencia y logos. Madrid: Alianza Editorial.

Zubiri, ., 1984, Inteligencia y razón. Madrid: Alianza Editorial.

Zubiri, X., 2001, Espacio. Tiempo. Materia: Madrid: Alianza Editorial.

Zubiri, X., 1979, Respectividad de lo real, Realitas 3-4:13-43 